\title{
TOWARDS A UNIFIED THEORETICAL MODEL OF OCEAN BACKSCATTER FOR WIND SPEED RETRIEVAL FROM SAR, SCATTEROMETER AND ALTIMETER
}

\author{
Craig ANDERSON, Trevor MACKLIN \\ BAE SYSTEMS Advanced Technology Centres, Great Baddow, Chelmsford, Essex CM2 8HN, UK \\ Tel. +44 (0) 1245 242654, Fax +44 (0) 1245 475244, email trevor.macklin@baesystems.com \\ Christine GOMMENGINGER, Meric SROKOSZ \\ Southampton Oceanography Centre, Empress Dock, Southampton, Hants SO14 3ZH, UK \\ Tel. +44 (0) 2380 596414, Fax +44 (0) 2380 596400, email M.Srokosz@soc.soton.ac.uk \\ Judith WOLF and Julia HARGREAVES \\ Proudman Oceanographic Laboratory, Birkenhead, Merseyside L43 7RA, UK \\ Tel.+44 (0) 151 6538633, Fax +44 (0) 151 6536269, email jaw@wpo.nerc.ac.uk
}

\begin{abstract}
INTRODUCTION
Empirical models of ocean radar backscatter have shown that spaceborne radars can provide quantitative information about wind fields. Examples include the CMOD and IFREMER-2 models developed for the ERS Wind Scatterometer. However, such models are limited because they do not include all the relevant physical effects, such as the influence of swell, rain, surface slicks and currents. Recent theoretical developments have addressed these aspects, and here we consider the construction of a 'unified' theoretical model, that is, one with a common set of parameters applicable to SAR, scatterometer and altimeter observations.
\end{abstract}

\section{MODEL DEVELOPMENT}

The model requires a scattering theory to be applied to a theoretical description of the ocean waveheight spectra. We compare predictions from the composite-surface and IEM (integral equation method) scattering models, using ocean spectra described by the models of Apel (1994), Elfouhaily et al. (1997) and Lemaire et al. (1999). We also incorporate a swell component and limited fetch, and we use published models of the perturbations to the wave spectrum due to the presence of rain, surface slicks or currents. The resulting model shows the sensitivity of the radar backscatter to all these parameters. It also predicts dependences on radar parameters which are relevant for future missions such as Envisat. Finally, it predicts the circumstances when the factors neglected by the empirical models such as CMOD will be significant. For example, it is found that the greatest effect on C-band, VV-polarised backscatter from swell is at low incidence angles, while from rain it is at high incidence angles (Figure 1). Note that the atmospheric attenuation from rain is not included in the modelling.

New empirical algorithms for the recovery of wind speeds from altimeter data are developed by applying nonlinear functionfitting procedures to an extensive set of Topex data collocated with buoy measurements. These eliminate a systematic bias in the Witter \& Chelton (1991) algorithm. The best results are obtained when using the altimeter Ku-band backscatter coefficient together with the altimeter significant wave height measured at $\mathrm{C}$ band (Figure 2).

\section{MODEL TESTS}

The theoretical model reproduces the empirical dependence on wind speed at nadir very well, but it under-predicts the empirical dependence on swell properties. This discrepancy is reduced if an influence of swell on the relation between wind stress and wind speed is incorporated.
This model is also tested by comparison with empirical scatterometer models at $\mathrm{C}$ and $\mathrm{Ku}$ band. The results indicate that the accuracy of the theoretical model is limited by the present understanding of the description of ocean wave spectra. For example, the IFREMER-2 model for $\mathrm{C}$ band, VV polarisation shows best agreement with the results from the Lemaire et al. (1999) spectrum, although there is a systematic difference at high wind speeds and high incidence angles (Figure 3). Also, the directional spread of waves is not well understood; this leads to a systematic discrepancy between the dependences of backscatter on wind direction predicted by the empirical and theoretical models.

\section{CONCLUSIONS}

We have discussed the development of a physically based model for wind-field retrieval, applicable to radar altimeters, SAR and scatterometers. The composite-surface model combined with the spectrum of Lemaire et al. (1999) agrees best with the tested data at all incidence angles. The significant slope is a free parameter in this spectrum, and is obtained by Lemaire et al. by fitting to radar data. Operationally, we would prefer to derive this parameter from a wave model such as WAM. However, the WAM results for idealised runs at different wind speeds give different values of significant slope to the values fitted by Lemaire et al. (Figure 4). This may be because the fitting of Lemaire et al. is affected by the presence of swell.

\section{ACKNOWLEDGEMENTS}

This work was funded by ESA (ESTEC) under Contract Number 12934/98/NL/GD.

\section{References:}

Apel, J.R., "An improved model of the ocean surface wave vector spectrum and its effects on radar backscatter", J. Geophys. Res., 99, pp 16269-16291, 1994.

Elfouhaily, T., et al., "A unified directional spectrum for long and short wind-driven waves", J. Geophys. Res., 102, pp 1578115796, 1997.

Lemaire, D., et al., "Full-range sea surface spectrum in nonfully developed state for scattering calculations", IEEE Trans. Geosci. Rem. Sens., GE-37, pp 1038-1051, 1999.

Witter, D.L. \& Chelton, D.B., "A Geosat altimeter wind speed algorithm and a method for altimeter wind speed algorithm development”, J. Geophys. Res., 96, pp 8853-8860, 1991. 
Figure 1. Sensitivity of $C$ band, VV polarised, backscatter to swell (top) and rain (bottom).
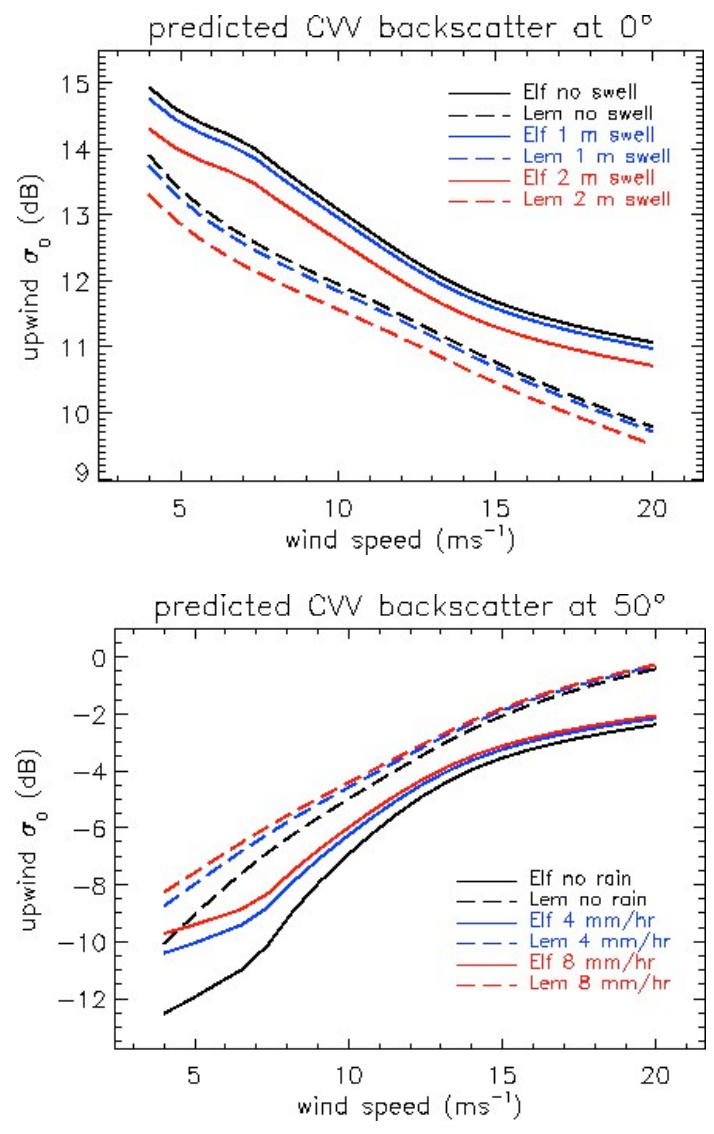

Figure 2. Results for two-parameter algorithm against Ku-band $\sigma_{0}$ (linear)(red points) compared with data (blue crosses) and Witter \& Chelton algorithm (green dots).

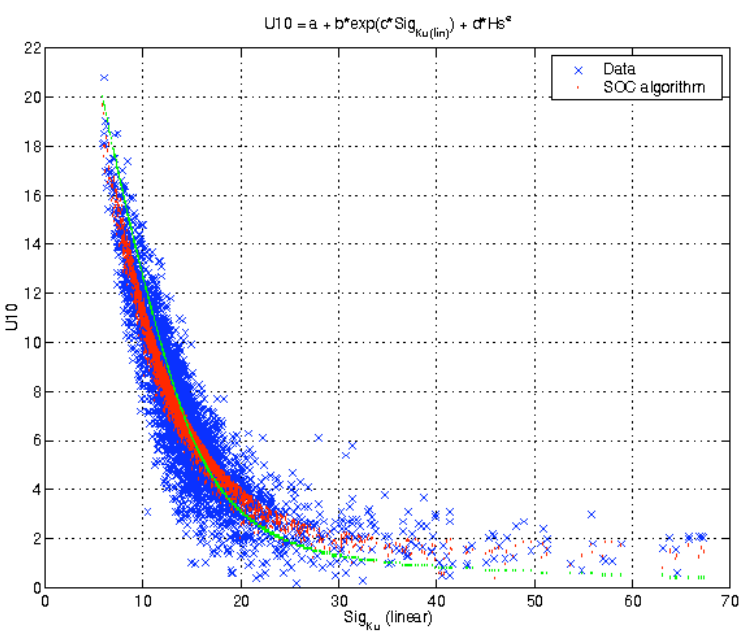

Figure 3. Comparison of models of ocean backscatter at $C$ band, $V V$ polarisation for $50^{\circ}$ incidence (top) and $25^{\circ}$ incidence (bottom).
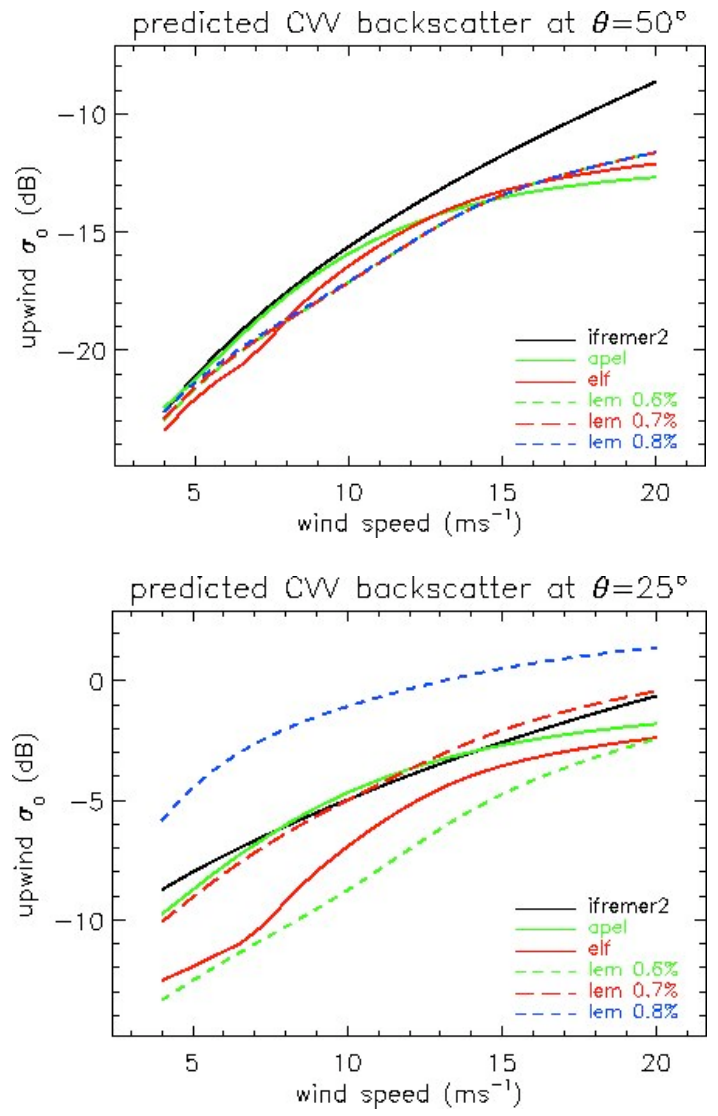

Figure 4. Significant slopes calculated from different spectra.

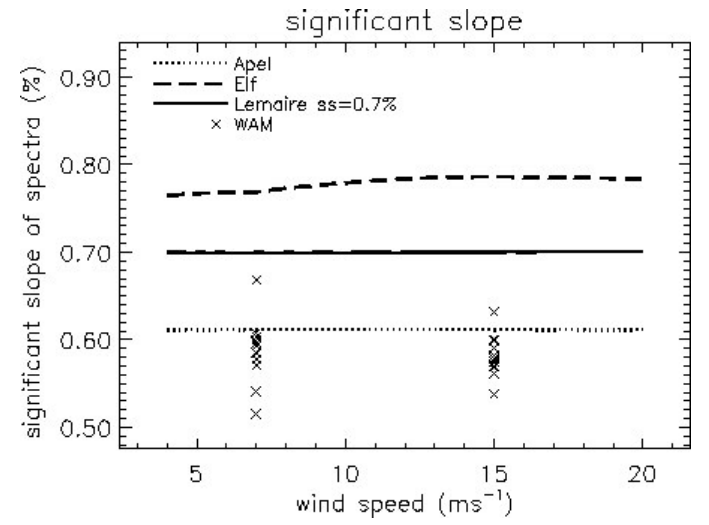

